\title{
REGRAS NA ESCOLA: PERCEPÇÃO DE ALUNOS DO ENSINO PÚBLICO
}

Andressa Carolina Scandelai Parra, Kelly Regina Conde, Luciana Aparecida Nogueira da Cruz.

Universidade Estadual Paulista - UNESP, Programa de Pós Graduação Em Ensino e Processos Formativos, São José do Rio Preto, SP. E-mail: andressa parra3@hotmail.com

\section{RESUMO}

O ambiente escolar apresenta aos alunos muitas regras que são importantes ao convívio social. Porém, muitas delas não são compreendidas ou não fazem sentido aos alunos, o que os leva a desrespeitá-las. Na presente pesquisa, buscamos conhecer a percepção de estudantes do Ensino Fundamental sobre regras na escola. Para isso, selecionamos itens específicos que tratam do tema regras de um instrumento que avaliou o clima escolar em escolas públicas. O método é do tipo descritivo e a natureza dos dados é quantitativa e correlacional. Participaram do estudo 1031 estudantes do 7으, 8ㅇ e 9o anos de quatro escolas públicas. Os resultados aqui apresentados são referentes aos itens que avaliam a elaboração, o cumprimento e a compreensão das regras. Concluímos com a análise dos resultados que as escolas não propiciam momentos de diálogo e participação dos alunos na elaboração das regras escolares.

Palavras-chave: Regras, Desenvolvimento Moral, Respeito, Ensino Fundamental, Autonomia.

\section{RULES IN SCHOOL: PERCEPTION OF STUDENTS OF PUBLIC EDUCATION}

\begin{abstract}
The school environment presents the students with many rules that are important for social living. However, many of them are not or are able to understand the students, which leads them to disrespect them. The present study seeks to know the perception of Elementary School students about rules in school. To the, select selected items and the method of the behavior was to select the evaluated the school climate in public schools. The type is descriptive and the nature of the data is quantitative and correlational. A total of 1031 students from the 7th, 8th and 9th grades of early childhood education participated in the study. The results are the items that should be analyzed, compliance and understanding of the rules. It concludes with an analysis of results as schools do not provide opportunities for dialogue and student participation in the elaboration of school rules.
\end{abstract}

Keywords: Rules, Moral Development, Respect, Elementary School, Autonomy. 


\section{INTRODUÇÃO}

As regras são muito importantes para a convivência humana, ou seja, a construção de regras é necessária para lidarmos com situações de conflitos, que fazem parte da convivência no ambiente escolar, por isso, nas escolas as regras são fundamentais para o funcionamento da instituição e harmonia nas relações sociais.

A presente pesquisa se fundamenta nos estudos de Piaget (1932/1994) sobre o desenvolvimento moral. Para ele, "Toda moral consiste num sistema de regras, e a essência de toda moralidade deve ser procurada no respeito que o indivíduo adquire por essas regras" (PIAGET, 1932/1994, p. 23). Consideramos importante compreender como as regras são construídas e/ou impostas nas escolas, pois

[...] costumeiramente nos apegamos a regras convencionais e deixamos de brigar por outras que realmente valem a pena. Não paramos para refletir quanto tempo gastamos com regras como não usar boné, chinelos, não levar figurinhas para a escola, entre outras. Pouco entendemos que uma regra só é boa quando há uma necessidade que garanta a dignidade do sujeito (TOGNETTA, LEME, VICENTIN, 2013, p.55).

Destacamos a importância da escola no processo de desenvolvimento moral, pois é um ambiente privilegiado onde crianças e adolescentes vivenciam experiências e realizam trocas com o coletivo, por isso a necessidade de levar sempre em consideração a dignidade do sujeito. É nas relações sociais que regras e normas são elaboradas e reelaboradas contribuindo para o desenvolvimento da autonomia moral, a qual buscamos por meio das relações cooperativas.

Na heteronomia moral, a legitimação das regras ocorre por meio da autoridade, que deve ser obedecida independentemente de haver um entendimento sobre a sua necessidade. Já na autonomia moral, o sujeito supera essa moral da obediência à autoridade externa, passando a submeter as regras ao crivo da inteligência.

As regras escolares muitas vezes são impostas de maneira coercitiva, tendendo a manter os indivíduos heterônomos, pois a eles basta obedecer àquilo que é estabelecido pelas autoridades escolares. Quando os alunos não participam da elaboração de regras contratuais, eles tendem a resistir à efetivação das mesmas, o que faz com que o desrespeito e o não cumprimento das regras interfira nas relações com a instituição, com o professor e com os colegas (LA TAILLE, 1996).

Preocupados com essa temática, temos como objetivo avaliar a percepção de estudantes do Ensino Fundamental público sobre a elaboração, participação e cumprimento das regras na instituição escolar.

\section{MÉTODOS}

Neste artigo, apresentamos parte dos resultados de uma pesquisa maior que avaliou a percepções dos integrantes de escolas públicas do noroeste paulista sobre o Clima Escolar (aprovada pelo Comitê de Ética em Pesquisa da Unesp, CAAE: 1.840.407).

A pesquisa é quantitativa com análise descritiva dos dados, tendo sido utilizados alguns itens específicos do instrumento usado para avaliar o clima escolar (VINHA; MORAES; MORO, 2017), na pesquisa maior (PAVANELI, 2018).

Os itens analisados são referentes a dimensão 3 do instrumento que avalia o clima escolar. Esta dimensão "[...] abrange a elaboração, conteúdo, legitimidade e equidade na aplicação das regras e sanções, identificando também os tipos de punição geralmente empregados. [...]" no ambiente escolar (VINHA, MORAIS e MORO, 2017, p. 10). Elencamos alguns itens dessa dimensão para serem analisados, sendo estes: 43 (Os estudantes participam da elaboração e das mudanças de regras da escola), 44 (Em geral, os adultos [professores, funcionários e direção] cumprem as regras da escola), 45 (Em geral, os estudantes cumprem as regras da escola), 46 (Os alunos 
conhecem e compreendem as regras) e 48 (Há momentos e espaços destinados a discutir os problemas de convivência, de disciplina e as regras na escola) (VINHA, MORAES e MORO, 2017).

Responderam à pesquisa 1031 alunos do 7으, 8으 e 9ㅇao anos do Ensino Fundamental de quatro escolas públicas estaduais do município de São José do Rio Preto. Segue a tabela com o perfil dos participantes:

Tabela 1. Frequência e porcentagem dos alunos que responderam à pesquisa

Fonte: autoras

\begin{tabular}{|c|c|c|c|c|c|c|}
\hline \multirow{3}{*}{$\begin{array}{l}\text { Escola } \\
A \\
(n=253)\end{array}$} & \multicolumn{2}{|l|}{ Sexo } & \multicolumn{2}{|c|}{ Ano Escolar } & \multicolumn{2}{|c|}{ Período escolar } \\
\hline & $\mathbf{F}$ & $\mathbf{M}$ & 70 & $64(25,3)$ & Matutino & Vespertino \\
\hline & $\begin{array}{l}115 \\
(45,4)\end{array}$ & $\begin{array}{l}138 \\
(54,5)\end{array}$ & $\begin{array}{l}80 \\
90\end{array}$ & $\begin{array}{l}91(35,7) \\
98(38,7)\end{array}$ & $\begin{array}{l}98 \\
(38,7)\end{array}$ & $\begin{array}{l}155 \\
(61,2)\end{array}$ \\
\hline $\begin{array}{l}\text { B } \\
(n=262)\end{array}$ & $\begin{array}{l}124 \\
(47,3)\end{array}$ & $\begin{array}{l}138 \\
(52,6)\end{array}$ & $\begin{array}{l}70 \\
80 \\
90\end{array}$ & $\begin{array}{l}85(32,4) \\
114(43,5) \\
63(24)\end{array}$ & $\begin{array}{l}29 \\
(11)\end{array}$ & $\begin{array}{l}233 \\
(88,9)\end{array}$ \\
\hline $\begin{array}{l}C \\
(n=228)\end{array}$ & $\begin{array}{l}113 \\
(49,5)\end{array}$ & $\begin{array}{l}115 \\
(50,4)\end{array}$ & $\begin{array}{l}70 \\
80 \\
90 \\
\end{array}$ & $\begin{array}{l}79(34,6) \\
73(32) \\
76(33,3)\end{array}$ & $\begin{array}{l}77 \\
(33,7)\end{array}$ & $\begin{array}{l}151 \\
(66,2)\end{array}$ \\
\hline $\begin{array}{l}\text { D } \\
(n=288)\end{array}$ & $\begin{array}{l}152 \\
(52,7)\end{array}$ & $\begin{array}{l}136 \\
(47,2)\end{array}$ & $\begin{array}{l}70 \\
80 \\
90\end{array}$ & $\begin{array}{l}97(33,6) \\
96(3,3) \\
95(32,9)\end{array}$ & $\begin{array}{l}169 \\
(58,6)\end{array}$ & $\begin{array}{l}119 \\
(41,3)\end{array}$ \\
\hline
\end{tabular}

Os dados da presente pesquisa foram coletados em quatro escolas públicas estaduais. As escolas $\mathrm{A}$ e $\mathrm{C}$ estão localizadas na região norte do município, sendo que essa região possui a maior concentração da população da cidade e também a de menor poder socioeconômico. A escola $B$ está localizada na zona sul da cidade, com uma concentração maior da população de classe média e a escola C está na zona leste, com uma população de média e baixa renda.

Após concedida autorização da Secretaria de Educação, dos gestores e dos professores, os alunos levaram para seus responsáveis assinarem o termo de Consentimento Livre e Esclarecido e, depois de concedida a autorização, sucedeu-se a coleta dos dados com os estudantes nas salas de informática de cada escola, que responderam ao questionário por meio da plataforma Survey monkey.

\section{RESULTADOS}

Apresentaremos a seguir as percepções dos estudantes em relação aos itens selecionados para análise (itens 43, 44, 45, 46, 47 e 48), que pertencem à dimensão 3 (regras, sanções e segurança na escola), do instrumento que avalia o clima escolar (VINHA, MORAIS e MORO, 2017). Às afirmações de cada item, os estudantes selecionavam as opções de resposta em uma escala Likert de quatro pontos: sempre, muitas vezes, algumas vezes e nunca. Os dados foram agrupados para melhor visualização, como podemos observar no Gráfico 1.

O item 43 investiga a percepção dos alunos sobre a participação da elaboração e das mudanças de regras da escola e os resultados indicam que $79,43 \%$ dos alunos afirmam que "nunca/algumas vezes" participam da elaboração das regras escolares.

Em relação ao item que afirma "em geral, os adultos (professores, funcionários e direção) cumprem as regras da escola" (item 44), 68,76\% dos alunos concordam que "muitas vezes/sempre" isso acontece. 0 item 45 avalia se "em geral, os estudantes cumprem as regras da escola" e indica que $72,26 \%$ dos alunos "nunca/algumas vezes" cumprem as regras da escola. 
A percepção dos alunos sobre conhecerem e compreenderam as regras da escola (item 46) indica que $60,92 \%$ deles "nunca/algumas vezes" compreendem. Sobre a escola ter espaços destinados a discutir os problemas de convivência, de disciplina e as regras na escola, 66,83\% dos alunos afirmam que "nunca/algumas vezes" existe esse espaço (item 48).

Figura 1. Percepção dos alunos sobre elaboração, participação e compreensão das regras. Fonte: autoras.

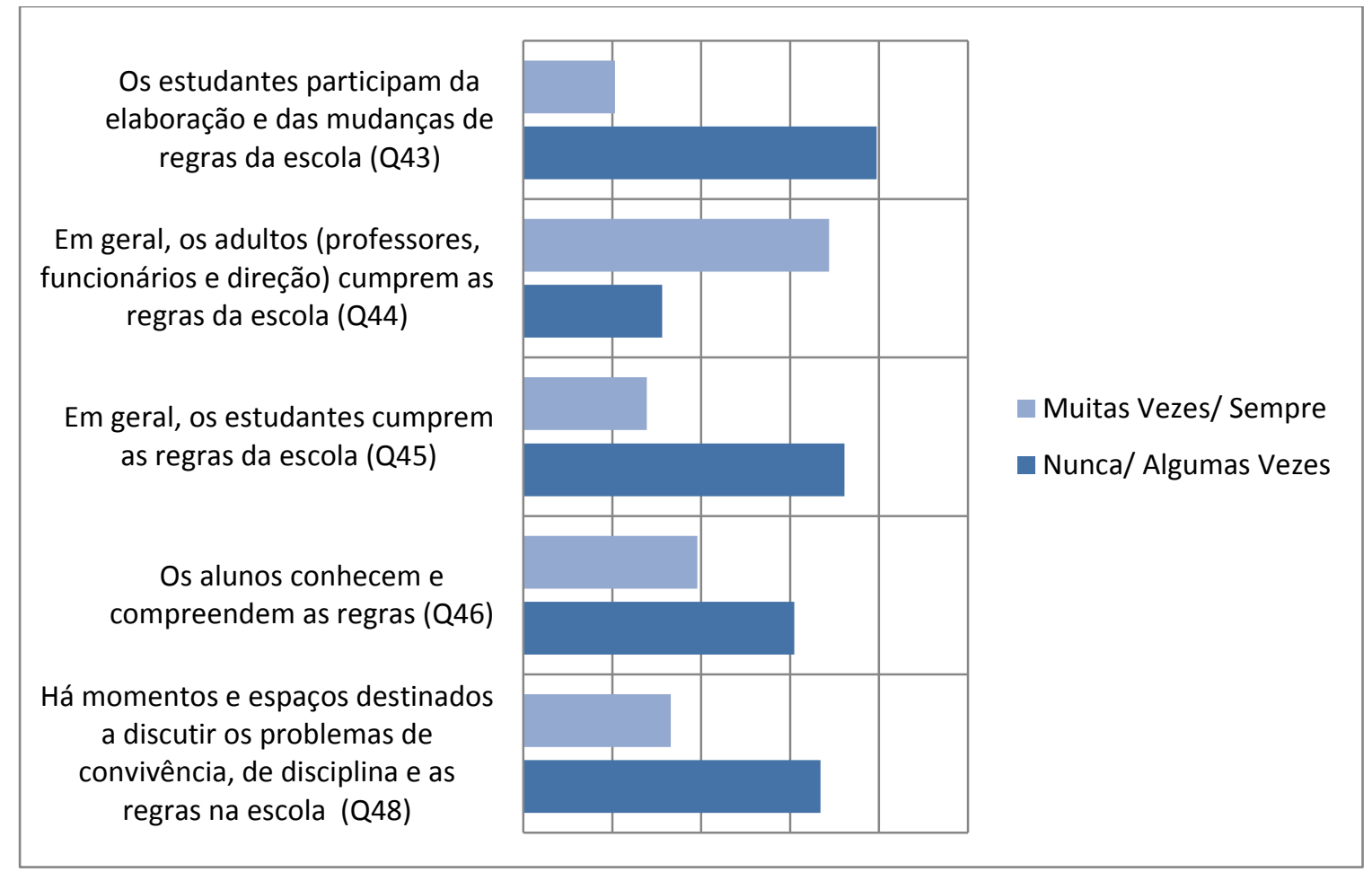

A discussão dos resultados obtidos sobre as regras escolares na percepção dos alunos serão apresentadas no próximo tópico.

\section{DISCUSSÃO}

De acordo com os dados, notamos que a participação dos alunos na elaboração e mudança das regras escolares não ocorre de forma efetiva sendo que

As regras possuem particularidades que as definem e diferenciam de outras regulamentações; são regidas por alguns princípios que incluem a flexibilidade e a particularidade; deve haver a participação efetiva de todos na construção das regras, como no cumprimento do que fora acordado (COLOMBO, 2018, p.85).

A participação dos alunos na elaboração das regras é imprescindível, pois além de possibilitar o exercício da democracia entre os envolvidos, tende a um maior comprometimento com as regras e o cumprimento daquilo que fora acordado entre os pares. Quando investigamos se os alunos cumprem as regras da escola, percebemos que as respostas vão ao encontro dos nossos pressupostos, pois os estudantes pesquisados afirmam que as regras em geral não são elaboradas por eles e, quando falam sobre o cumprimento das regras, uma grande porcentagem de alunos afirma não cumpri-las. Logo, temos indícios de que essa situação poderia ser diferente caso eles participassem da elaboração das regras, tendendo a segui-las com mais frequência.

Para Piaget (1932/1994), quando não há o cumprimento das regras é pelo fato de não ter sido atribuído um sentido a elas por parte dos adolescentes. Para que haja o cumprimento dessas regras, Puig (2004) afirma que é de extrema necessidade vivenciar as regras no convívio cotidiano, 
pois para conhecer as normas é primordial as saber utilizar, tendo em vista que cada situação nova possui uma necessidade única.

Ainda ao encontro dos itens anteriores, os estudantes tendem a não conhecer e não compreender os princípios e o sentido das regras por não participarem da elaboração das regras.

Destacamos no item sobre ter momentos e espaços destinados a discutir os problemas de convivência, de disciplina e as regras na escola, $66,83 \%$ dos alunos que responderam não existir nas escolas estes espaços. Esse dado mostra-se alarmante, uma vez que promover reflexões e propiciar que os adolescentes participem da construção das regras escolares são importantes ao desenvolvimento moral, como afirma Puig ao enfatizar que este espaços possibilitam "participar em atividades e práticas, entrar em um fluxo de encontros informativos, e formar vínculos afetivos com seus participantes" (PUIG, 2004, p. 177). Entendemos que estas são atividades necessárias para o ambiente escolar, movimentando o exercício do pensamento e de discussões sobre os conflitos existentes.

\section{CONSIDERAÇÕES FINAIS}

A escola deve ser o lugar onde é possível discutir e elaborar regras pautadas em princípios e valores morais, sendo imprescindível pensar em intervenções para promover espaços que permitam a tomadas de decisões pelos alunos, momentos de discussões sobre os conflitos e a construção de relações respeitosas entre professores, alunos e os demais integrantes da comunidade escolar. Infelizmente, na realidade, o que vemos são escolas que priorizam regras convencionais mais do que as morais e prevalecem as relações coercitivas, atribuindo punições expiatórias aos descumprimentos de regras, que são frequentes uma vez que os alunos não participam de sua elaboração, não internalizando essas regras e muitas vezes nem mesmo as compreendendo.

Acreditamos que um ambiente onde o clima em que as relações e sensações dos integrantes daquele ambiente são positivas seja mais favorável ao aprendizado e desenvolvimento de todos. Entendemos que identificar as características do clima das escolas possibilita compreender os fatores que influenciam nos problemas escolares para melhorar as relações de convivência ética nas escolas e na sociedade como um todo. Se considerarmos que as relações respeitosas que promovem um clima escolar favorável são uma variável importante na construção de uma personalidade moral, a formação de indivíduos autônomos contribui para a compreensão de regras e empatia dos alunos para que tenham um sentimento de pertencimento ao meio em que estão inseridos. A imposição de regras só reforça a moral heterônoma.

Percebemos que o papel do professor é muito importante para o desenvolvimento de uma personalidade moral e que cabe aos profissionais da educação proporcionar um ambiente no qual a criança seja educada para que seu desenvolvimento tenda à autonomia. As relações e sensações positivas dos integrantes daquele ambiente são favoráveis ao aprendizado e desenvolvimento de todos, por isso é necessário permitir que o respeito mútuo seja construído em relações de cooperação e assegurar a troca de experiências tanto entre alunos como entre alunos e professores.

\section{REFERÊNCIAS}

COLOMBO, T. F. S. A convivência na escola a partir da perspectiva de alunos e professores: investigando o clima e sua relação com o desempenho escolar em uma instituição de ensino fundamental II e médio. Tese de doutorado do Programa de Pós-Graduação em Educação da Faculdade de Filosofia e Ciências, da Universidade Estadual Paulista - UNESP - Marília, 2018.

LA TAILE, Y. A indisciplina e o sentimento de vergonha. In: Aquino, Júlio G. (org.). Indisciplina na escola, alternativas teóricas e práticas. São Paulo: Summus, 1996. 
PAVANELI, Camila Fernanda Dias. Clima escolar: percepções de alunos, professores e gestores de escolas estaduais do Ensino Fundamental II. 155p. Dissertação de Mestrado Acadêmico - Instituto de Biociências, Letras e Ciências Exatas - Universidade Estadual Paulista (IBILCE/UNESP), São José do Rio Preto/SP, 2018

PIAGET, J. O Juízo Moral na Criança. Tradução Elzon Lenardon. - São Paulo: Summus, 1994.

PUIG, J. M. Práticas Morais: uma abordagem sociocultural da Educação Moral. São Paulo: Editora Moderna, 2004.

TOGNETTA, L. R. P.; LEME, M. I. S.; VICENTIN, V. F. Quando os conflitos nos pertencem: Uma reflexão sobre as regras e a intervenção aos conflitos na escola que pretende formar para a autonomia. Campinas, SP. Mercado de Letras, 2013.

VINHA, T. P.; MORAIS, A. de; MORO, A. (org) Manual de orientação para a aplicação dos questionários que avaliam o clima escolar. Campinas, SP:FE/UNICAMP, 2017. 